\title{
Rational Value and Significance in Visual Communication Design
}

\author{
Sun Yu \\ Yancheng Teachers University, Art and design institute, Yancheng of Jiangsu Province, 224000
}

Keywords: visual communication design; Rational value; Instrumental rationality; Rational value

\begin{abstract}
The era of social change, the change of consumer demand, the development of natural science and social science have had a great influence on the visual communication design, which is both opportunity and challenge, also let people to rethink and explore rational value and method of visual communication design, seek the significance of the rational value of visual communication design, make visual communication design play a better rational value function, to better serve the needs of society.
\end{abstract}

\section{Visual Communication Design and Rational}

Rational belong to the category of philosophy, has a profound connotation and denotation, social value is extremely high and to explore the rationality of social value, is bound to mention the great philosopher Max weber about the reason of substance and the rational model, two kinds of model reveals the we often used in problem solving rational concepts and rational way.But from the perspective of theory of value, human rational responses to the environment, but not limited to survival and to solve the problem, people hope life more meaningful, a spiritual pursuit, namely rational value model.

Visual communication design of the rational model includes both instrumental rationality and value rationality, rational elements including rational theory and rational practice of two, theory refers to the rational concept in the design of visual communication, including all associated with visual communication design visual cognitive laws of physiology, psychology, design and aesthetic judgment, etc., and all related to social sustainable development, value standard and social ethics of humanistic thought, practice aspect refers to the rational design of visual communication art skill operation, is used to implement the visual communication design of practical value, efficiency value, spiritual and cultural value. In the visual communication design theory and practice of rational aspects complement each other, complement each other, the former provide theoretical guidance for the latter, and the latter provides the empirical basis for the former, be short of one cannot. But their respective have relatively independent Chinese, logic of the theory of integrity and is independent of necessity of the development time, cannot replace each other.

\section{From the tool rationality to value rationality}

Connotation of the concept of rational is expanding, so the rational design of visual communication is also constantly improving. With the development of modernism design problems we are facing an increasingly complex, it reminds us, visual communication design is not enough to only rely on instrumental rationality, also need the support of rational value and guidance.The replacement of the modern consumer groups, more different design products, and the whole society on the responsibility of the designer, the design professional ethics put forward higher standards, people began to pay more attention to tool rationality to bring the adverse effect of visual communication design, more rational support call value.

Max weber put forward the characteristics of instrumental rationality: "utilitarian and practical, universal validity, maneuverability.

The major form of instrumental rationality is: 
Science and technology in the design of visual communication include photography technology, printing technology and electronic technology, these technologies deeply influence the quality of the visual communication design and scope.

Which printing design content is widespread, such as printing tools, printing materials and printing process, the development course from the ancient period of manual operation, to modern machine operation, and finally came to the modern computer control operation.Especially in the modern period of machine operation, the use of the physical, optical, chemical machinery, such as the technology, the improvement of printing quality and efficiency of contribution, to become the mainstream of visual communication design, print design provides information for the public life with light channels, expand the speed of information transmission, the breadth and depth, is also deeply influenced the form of visual communication design, the design method.

Applied in the visual communication design of visual physiology and the psychological cognition rule, can play a role effectively communicated, as a tool, can greatly improve visual communication design of information exchange and communication between acceptance and cognition, the designer can be used to eliminate to recognize and interpret design language tool, also can improve the effectiveness of the artistic expression, let design work in addition to the information needed to complete the message consumer task, still can make consumers have good aesthetic experience.

Humanized design the evaluation criterion of art and design in addition to stimulate consumption, more should be people-oriented. Design according to the needs of the people.The design idea of the past to stimulate consumption is "only", this kind of design concept under the guidance of design caused many problems, such as repetition, energy resources waste, ecological environment destruction and so on, and humanization design and green design adhere to the people-oriented, and environment friendly, make full use of resources, protect the ecological environment.Humanization design and green design concept is used in the design of the visual communication, whether thoughts or expression, and found a new, more profound connotation of life.In economic development, age in progress, people's consumption view in the change, under the guidance of sustainable development, the reasonable consumption, green consumption, has been recognized, and the pursuit of healthy consumption, and the humanization design and green design in the visual communication design just cater to consumer demand, and promote the spread of the new consumption.Therefore, designers should cause enough attention, and actively applied in practice, many developed countries have taken effective measures to regulate the behavior of visual communication design.

Visual communication design influence on social development including the dominant influence and potential. Although influence is limited, but not too much value or ignored.We can't expect designers through visual communication to solve all social problems, more can't ask the designers to undertake the construction of value system role, but we can't ignore its influence may, otherwise don't respect for consumers, not responsible to society. Visual communication design is not only in promoting a product or service, but also in the boot a way of life. Designers will naturally will be reflected his value orientation in the act of design, through the design activities to meet the needs of society, the value and the demand to promote each other.So this value must be rational thinking and method, the value of visual communication design should include ethical and moral ideal, in order to meet the human pursuit of the humanistic spirit and the sustainable development goals.

\section{Rational Value in Visual Communication Design}

Growing impetus of social progress in science and technology, the impact on the visual communication design is more extensive. Whenever a new technology appears, will cause the change of consumption demand, visual communication design development and changes accordingly.Visual communication design tools, materials, techniques are changing, and innovative design concept and design method, and the solid foundation on which innovation is rational design philosophy and methods.Modern visual communication design is present the diversity, dynamism, and computerized, optimization, clever use of science and technology, with a scientific rational 
ideas and methodology to solve the design problem more, in order to construct and perfect the design theory and practice.

Rational ideas and methods in the design of visual communication, is the need of times development, is the need of real business competition, while the rational value of visual communication design, is the development of visual communication design in the process of gradually accumulated abundant achievements, its development has been inseparable from the rational concept and method of support.

As outstanding elements of a culture of pragmatism, the instrumental rationality of visual communication design objective of market competition environment, promote the progress of the social material civilization, in turn, the progress of material civilization led to the further development of the design, formed the two-way interaction between the demand and design;As human thought and spirit culture of creation good elements, visual communication design of the rational value into the needs of the development of the human health, reasonable promotes the construction of spiritual civilization, in turn, helps to promote spiritual civilization construction design of their own value. Rational value of visual communication design, as it were, to form the two-way interaction between requirements and the design of the benign development.

In China, the promotion of the rational concept and method to study, is the premise of development of modern design education system.By 2012, our country already has more than one thousand colleges and universities set up professional design art, joined in the graduate design industry more than ten thousand people a year, although the relatively large size and number, but the overall design ability and design quality the good and bad are intermingled.All colleges and universities in the design of the guidance of education resource configuration, design the teaching ideas, design the teaching method of the application, there is no standard, unscientific and irrational problems, its design art specialized teaching achievement evaluation system is not perfect.

And social demand is the intelligent design talent, need to have a strong practical design ability of the designer, the design of the school education has obviously not meet the demand of the society, investigate its root, the lack of rational design thoughts and methods is an important cause of cannot be ignored, if be reasonable application, on the one hand, help to formulate scientific standards to standardize the visual communication design education teaching, learning, management, etc.;Provide serious academic distributes, on the other hand, the implementation of the visual communication design education and the evaluation process, ensure the healthy development of visual communication design education brand spirit, communicate the brand connotation of the city, is also the basis of constructing the audience's perception and memory of city, this is the city brand symbol.City brand symbol is the height of the strategic position of a city, it should be included in the city symbol.City symbol is the foundation of the city brand symbol, city brand symbol is the symbol of refining.Compared with the urban symbol, city brand more transmitted symbols, and representative, identification, and regional characteristics, and has a high profile. (5) Mark recognition personalized strategy thinking can make our city differences and unique urban culture gene, avoid blindly follow the flow. When many cities have the pursuit of "innovation". It is often embodied in the positioning of reverse thinking and strategy. In most cities are seeking, for example, when the economy, the concept of internationalization support, the chengdu city in western China is put forward the concept of the "garden city" in the world.

\section{Conclusion}

From the "secondary" urbanization voice swept across the world. Today's society, media, technology, cultural flows are endowed with "secondary" urbanization new richness. Contemporary China's urbanization process has more special characteristics. In parts of China has not yet been completed based on the industrialization of the urbanization development, but at the same time facing a second wave of urbanization. Therefore, two kinds of process of urbanization under the mixed makes cities especially in the western underdeveloped region in our country present a longitudinal three-dimensional record line urbanization development. Which exist in the traditional 
city symbol differences for the typical traditional city space shaping process of text (similar to the statue of liberty in New York and Paris Eiffel Tower became the symbol of the city, such as the bird's nest, the Oriental pearl TV tower, guangzhou tower, etc.), and presents a new digital secondary urbanization comprehensive comprehensive perception of the signifying chain, especially the virtual city and the spread of the online attention. Therefore, the whole of China's city brand positioning is more in need of top level design. Because in the process of high-speed urbanization, extremely easy because of the pursuit of industrialization base of urban scale expansion and the extroverted expansion, while ignoring secondary connotation promotion of urbanization and urban structure of "humanistic" and in the service of the forward-looking considerations of life. Therefore, in the process of city brand positioning, we could see much city highlights its own "commercial" "innovation", "wealth", lost its own some unique cultural gene. This long especially need a kind of based on the perspective of cultural semiotics to achieve urban brand positioning marked "sex". For mainland China is facing rapid development of urbanization, the perspective of the cultural symbol it is of special significance.

\section{References}

[1] Shou-zhi wang modern architectural history in the world, China building industry press, 1999), p. 107

[2] Li yining, "li yining: traditional urbanization model is not suitable for China's national conditions", "sohu finance and economics",http:/ /business. Sohu.com/20130111/n363132336.shtml

[3] Zhao Henyi semiotics: principle and deduction, nanjing university press, 2011), p. 281.

[4] Bronwen Martin, Felizitas Ringham. Key Terms in Semiotics, Con-tinuum International Publishing Group, 2006, p.41.

[5] Xu Fangyuan, Li Qianyi "China of the present situation of the spread of brand symbol thinking", "city brand communication research in China". 